J. clin. Path. (1947), 1, 2.

\title{
THE LABORATORY DIAGNOSIS OF VIRUS INFECTIONS OF MAN: A REVIEW
}

\author{
BY \\ S. P. BEDSON \\ London Hospital and Medical College
}

(RECEIVED FOR PUBLICATION, JULY 25, 1947)

The last fifteen years have seen a considerable advance in our knowledge of viruses. Admittedly it is still impossible to say whether or not viruses are living micro-organisms: there is even some doubt as to whether all those agents which we group together as viruses are of the same nature. But, interesting though these particular problems are, they have no direct bearing on the practical question of the diagnosis and control of virus disease, since for these purposes viruses can be regarded as micro-organisms. And the inability to answer these questions unequivocally does not mean that in other respects our knowledge of viruses has not made great strides. Many of the larger viruses have been stained and seen with the ordinary microscope, and the greater power of microscopic resolution obtainable by the use of ultra-violet light and a quartz optical system comprising a dark-ground condenser -an advantage which we owe largely to the work of J. E. Barnard in this country-has made possible the photography of these large viruses in an unstained and unaltered state, and has also brought some of the smaller viruses within the range of visibility. Furthermore, the introduction of the electron microscope, with its still greater powers of resolution, enables us to see even the smallest virus.

We are no longer confined to the use of animals for the cultivation of viruses. The adaptation of the technique of tissue culture to this purpose, and the use of the developing hen's or duck's egg - which we owe to the ingenuity of the American pathologist Goodpasture-have provided us with simple means for growing many of the animal viruses in the laboratory. And when we turn to the question of those serological reactions, the precipitin, agglutination, and complement fixation tests which have been of such invaluable service in the study of bacteria and bacterial disease, we find that, contrary to what was at one time thought, these methods are applicable to virus work. It is the purpose of this article to consider some of this recent work and its application to the diagnosis of diseases of man of virus aetiology.

\section{Microscopy}

Demonstration of viruses by means of the microscope.-Sixty-one years ago Buist announced that he had succeeded in demonstrating particles with the appearance of minute cocci in smears made from vaccinial lesions (see Gordon, 1937); he concluded that these were the virus. As a recent American writer has remarked: "Buist was a man far ahead of his time; his contemporaries were not merely sceptical, they were not even interested." In 1904 Borrel published a paper on the virus of fowlpox, in which he showed that, by the use of Loeffler's flagella stain, minute coccal bodies could be demonstrated in smears of virulent material, and he considered these to be the virus. Two years later Paschen of Hamburg, using a very similar technique to Borrel, rediscovered the virus of vaccinia. Although this work did not pass unnoticed it did not receive general acceptance, in fact most bacteriologists adopted a sceptical attitude which it took nearly twenty years to dispel. The reason for this scepticism was due largely to the fact that the staining methods then employed, although producing admirable preparations in the hands of the expert, gave rise to artefacts bearing a remarkably close resemblance to stained virus particles, and the tendency to dismiss all these appearances as artefacts was all too readily adopted.

Since then, improved methods of staining and the devising of technical procedures for the separation of virus from the non-specific material in the crude suspensions of virulent material have made it possible to show that the particles one can stain and see in smear preparations are, in fact, virus. In this work, fractional centrifugation has played an important part. Saline suspensions of virulent 
material are first centrifuged at a relatively low speed to throw down gross particles of tissue, and the resulting supernatant is then spun at a speed sufficient to deposit the virus. After removing the supernatant fluid, the deposit is resuspended in saline and centrifugation, first at a low speed and then at a high speed, is repeated. A deposit is finally obtained which consists very largely of particles resembling in size and staining properties those seen in the smears made from the original virulent material and thought to be virus, and the demonstration that the virulence of the original suspension has moved with the particles and that they react specifically with a known antiserum completes the proof that virus and particles are one and the same. There is, therefore, no doubt that the larger viruses can be seen with the microscope. They look like minute micro-organisms, and this conception of their nature finds support in the dark-ground photomicrographs that Barnard has produced of unfixed and unstained viruses.

Turning now to the practical application of this work to the diagnosis of virus disease, it is obvious that direct microscopy can be of use only in the case of the large viruses. Even here the limitations of the method are greater than in bacterial infections. The largest viruses are so much smaller than bacteria that they can be detected only if they are present in considerable numbers, and the occasions when their identity can be assumed because they have been seen in smear preparation are very few. However, the method is not without value and it finds its use particularly in the diagnosis of infections due to that group of large viruses which are distinguished from the others by staining by Castaneda's or Macchiavello's methods. For that matter, this group possesses other characteristics that mark it off from the rest: the viruses are larger, and when they multiply they present a regular sequence of morphological change, recalling those changes in size and shape which a bacterium often undergoes when multiplying. This group contains amongst others the agents of trachoma, inclusion conjunctivitis or inclusion blenorrhoea, lymphogranuloma venereum, and psittacosis. The use of microscopy in confirming the diagnosis of trachoma, particularly in its early stages, is well known. Halberstaedter and von Prowazek (1907) were first to demonstrate the characteristic cytoplasmic inclusions in the conjunctival epithelium in this condition, and the more recent work of Thygeson and Proctor (1935) has shown that the particles which occur both free and inside the cells and which are readily stained by Castaneda or Giemsa are, in fact, the virus.
Inclusion conjunctivitis. - Infection with the closely related virus of inclusion conjunctivitis is of greater interest to us, since it is of commoner occurrence than trachoma in this country, This virus is morphologically indistinguishable from that of trachoma; the exact relationship of the two, though obviously close, is yet to be determined. Like the trachoma virus, it is a parasite of man and is found producing infection of the conjunctiva and the mucous membrane of the cervix and the male urethra. Cells infected with this virus present inclusions which in situation, structure, and staining properties bear an extremely close resemblance to those of trachoma. They consist of masses of virus particles held together by inclusion material which is basophilic and scanty in amount. These inclusions differ, therefore, from what one might call the "typical" virus inclusion, in which the inclusion material is acidophil and present in such amount as completely to mask the virus, and it is this scantiness of inclusion material in the inclusions produced by the group of Castaneda-positive viruses which has made it so much easier to study and recognize their true structure. Like the other members of this group, the virus of inclusion conjunctivitis shows the sequence of developmental forms to which reference has already been made. The large forms, which are almost the size of staphylococci, have been called by Lindner (1910) "initial bodies," since in his opinion, they represent the initial stage in the development of the virus, a view which is fully supported by recent work. As the virus multipliesand all appearances suggest that it does so by simple division-smaller and smaller forms are produced until, when the colony is fully grown and the cell is ready to break down and discharge its virus content, all the virus is in the form of elementary bodies.

Inclusion conjunctivitis occurs either as a neonatal infection, when it is acquired in precisely the same way as gonococcal ophthalmia, or in older children or adults, when it is often called swimming-bath conjunctivitis. Both forms are associated with inflammation of the conjunctiva and some discharge; scattered follicles may be present. Diagnosis is made by the microscopy of conjunctival scrapings suitably stained, and some idea of the incidence of the neonatal form can be gathered from a recent paper by Sorsby and others (1944), who found twenty-seven cases in 269 of all forms of conjunctivitis in infants.

Cervicitis and urethritis.-Infection of the mucosa of the female genital tract is usually silent, but it can be revealed by the examination of stained smears of cervical scrapings. In the male, infection of the 
urethra takes a subacute form which may become chronic and persist for months; this infection of the genital tract is transmitted by sexual intercourse and, although it undoubtedly occurs in this country, it appears to be uncommon.

Psittacosis.-The virus of psittacosis is another that can be recogniżed microscopically; and, although it is not suggested that direct microscopy is of value as a diagnostic procedure in human infections with this virus, it is undoubtedly of use in the case of infection of birds. It is often possible to find the virus in smears made from the spleen, which is commonly enlarged, or with material from the air 'sacs, where infection often resides, and so to make an early diagnosis.

Lymphogranuloma venereum.-Lymphogranuloma venereum virus, another member of the Castanedapositive group, can also be detected in suitably stained smears of the pus from the inguinal buboes which occur in the male and when the primary lesion is penile, or when it is situated in the anterior part of the genital tract of the female. Though possibly worth making, this investigation has not the same value in the diagnosis of lymphogranuloma venereum as isolation of the virus, the Frei test, or the complement fixation reaction.

Smallpox.-As a further example of the diagnostic value of the microscopical demonstration of virus, mention might be made of its use in smallpox. This virus is of a size readily visible under the microscope, and a number of staining methods are available for its demonstration, sbme of which, such as the alkaline methyl-violet method of Gutstein (1937), are quite simple. The virus is present in quantity in the skin lesions and, as van Rooyen and Illingworth (1944) have shown, microscopic examination of suitably stained smears made from scrapings obtained from the base of papules or vesicles can be of considerable diagnostic value. In the cutaneous lesions due to herpes febrilis, zoster, or varicella, the virus particles, though present and staining by the methods applicable to variola, are neither so numerous nor so large as variola virus. Van Rooyen and Illingworth used Paschen's staining method. Commenting on this diagnostic procedure, Downie (1946) states a preference for Gutstein's stain and points out that smears made from pustular lesions or crusts are unreliable, that a negative result does not exclude smallpox, and that the test would not differentiate between the lesions of smallpox and vaccinia.

Demonstration of specific histological changes.Quite apart from the possibility of demonstrating the virus itself, there are, in many virus diseases, demonstrable histological changes in the infected cells which are sufficiently distinctive to be of diagnostic value. These are the inclusion bodies found in the cytoplasm or the nucleus of the affected cells, bodies of varying size, usually homogeneous in appearance and acidophil in staining reaction, which may come to occupy the major part of the nucleus or a considerable part of the cell's cytoplasm. Doubt still exists as to the exact nature of the nuclear inclusions, but it has been shown that many cytoplasmic inclusions are virus colonies, masses of virus embedded in a matrix of homogeneous material. It is this latter material which gives to many of these inclusions their appearance of homogeneity and affinity for acid dyes. In the case of the cytoplasmic inclusions produced by the Castaneda-positive viruses, inclusion material is in insufficient quantity to mask the virus particles, and these can usually be readily seen either in Castanedaor Giemsa-stained preparations. Even where the inclusions appear homogeneous when fixed and stained, it is still possible, as Barnard has shown in the case of ectromelia, to demonstrate the true nature of the inclusion by using dark-ground illumination. The difference in refractility of virus and inclusion material shows up the former as bright dots.

At one time it was thought that only infection with a virus could produce inclusion bodies, but it is now known that very similar appearanices can be produced experimentally by other means. This applies particularly to nuclear inclusions. None the less, the finding of inclusion bodies can be taken as presumptive evidence of a virus infection, and in some instances their demonstration has diagnostic value. The finding of Negri bodies, the acidophil cytoplasmic inclusions produced by rabies virus in nerve cells, confirms the diagnosis of suspected rabies in the dog. And mention has already been made of the demonstration of the HalberstaedterProwazek bodies in trachoma and the similar inclusions in inclusion conjunctivitis, cervicitis, and urethritis as diagnostic procedures. Paul's test for smallpox, which depended on the production of lesions in the rabbit's cornea characterized by cytoplasmic inclusions, has been largely superseded by the demonstration of the infective agent in the skin lesions either by direct microscopy or by the complement fixation test.

\section{Isolation of the Virus}

If the application of microscopy to the diagnosis of virus infections has been dealt with at some length this has been done deliberately in order to 
emphasize that, contrary to common belief, many viruses are sufficiently large to be seen and recognized by means of the microscope. The limitations of this procedure have not, however, been lost to sight, and, in virus infections as in any other infective process, the aim of the laboratory should be the isolation and identification of the infective agent. Unfortunately this is less easy to achieve than in bacterial disease. Not only is the isolation and identification of a virus a lengthy and often difficult procedure, involving the infection of animals or embryonated eggs, the study of the histological lesions produced by this infection, and the application of serological tests usually in the form of the neutralization reaction, but there are quite a number of viruses infecting man for which a suitable experimental animal has not been found. The viruses of zoster, varicella, and infective hepatitis exemplify this: to them, man alone would seem to be susceptible. Or it may be that the only susceptible species of animal is so expensive as to preclude its routine use; it is this factor, probably more than any other, which has delayed our understanding of poliomyelitis and its epidemiology. Even where a virus can be isolated by the use of the incubated egg or an inexpensive animal, the time taken to establish and identify it is too long to make the procedure of immediate diagnostic importance. That does not mean that every attempt should not be made to isolate the agent of a suspected virus infection, because this should, of course, always be done where the diagnosis is in doubt. The following examples illustrate some of the commoner uses of this form of investigation.

Egg inoculation.-It is at times important to know whether an outbreak of clinical influenza is due to one of the known influenza viruses and, if so, which one. This might be necessary, for instance, at the commencement of an epidemic when prophylactic immunization is contemplated; and, though at one time the ferret would have been chosen as the most suitable animal for the purpose, probably the incubated hen's egg would now be the choice. Hirst (1942 and 1945) has found the injection of naso-pharyngeal washings into the amniotic sac of thirteen-day eggs slightly superior to ferret inoculation for the isolation of influenza $A$ virus, an observation confirmed by Burnet and others (1942). And Beveridge and others (1944) employed the same method successfully for the isolation of influenza B virus. The combination of penicillin and sulphadiazine with the crude washings does away with the necessity for filtration. The embryonic membranes of the developing hen's or duck's egg - the amniotic, allantoic, and yolk sacs and the chorio-allantoisprovide admirable means for the cultivation of a number of viruses to which man is susceptible; in addition to influenza $A$ and $B$, the viruses of herpes simplex, psittacosis, lymphogranuloma venereum, mumps, measles, lymphocytic meningitis, and smallpox can all be grown on one or other of these membranes. Incidentally, North and others (1944) utilized inoculation of the chorio-allantois with suspensions of skin crusts in the diagnosis of smallpox, a procedure the value of which has been fully confirmed by Downie (1946) and Downie and Dumbell (1947).

Value of animal inoculation.-Invaluable though the egg technique has proved in virus work, it has by no means superseded the use of experimental animals, for there are occasions when only the latter are suitable to the work in hand. This is true, for instance, of poliomyelitis, where inoculation of the monkey is our only means of demonstrating the presence of the virus. Even in those cases where the virus sought will infect both eggs and animals it is advantageous to use both; it increases the chance of success and it may well be that the disease produced in the animal is more distinctive than the changes resulting from infection of the egg. The latter may, in fact, be so inconspicuous as to make their detection difficult and uncertain, as in infection of the chorio-allantois with the virus of lymphocytic chorio-meningitis. Or, as recent work on rinderpest has shown (Shope and others, 1946), a virus may multiply within the developing egg without producing any detectable naked-eye or histological changes or even death of the embryo.

Meningitis.-So where both egg and animal are available for our purpose we use both. This is true, for instance, in the investigation of acute aseptic meningitis, a syndrome due to a number of viruses, some of which have been identified. Of these, the virus of lymphocytic choriomeningitis of Armstrong and Lillie is responsible for about one-third of cases. At any rate, that would appear to be so in North America, though one has the impression that it is a less frequent cause of benign meningitis in this country. Other viruses which have been found producing this form of meningitis are the pseudo lymphocytic choriomeningitis virus of MacCallum, Findlay, and Scott (1939) and the virus of lymphogranuloma venereum. Infection with the last-named virus may rarely present as a meningitis (Sabin and Aring, 1942), and the virus of MacCallum and Findlay has been isolated on only two occasions; more than half the cases of this condition are due to a virus or viruses yet to be identified. The three 
known causal agents are to be found in the cerebrospinal fluid, and all these are pathogenic for the mouse and guinea-pig. Wherever the diagnosis of acute aseptic meningitis is in question, cerebrospinal fluid collected as early in the disease as possible should be injected intracerebrally in mice and subcutaneously in the thigh of guinea-pigs. Should any of the three viruses be present, encephalitis may develop in one or more of the mice, and the virus so isolated can be established and studied. The virus of Armstrong and Lillie (1934) will often infect the guinea-pig, producing a generalized infection with pyrexia, wasting, and salivation, the animal dying usually in from nine to sixteen days. Should the case of meningitis prove to be tuberculous, and in the early stages of this condition the differential diagnosis from benign lymphocytic meningitis of virus origin may well arise, the mice will remain well whereas the guinea-pigs will develop tuberculosis.

Lymphogranuloma venereum.-In addition to producing an encephalitis when inoculated intracerebrally in mice, lymphogranuloma virus also produces a local lesion when injected sub-cutaneously in the guinea-pig's thigh, and an enlargement of the inguinal lymph nodes occurs; the lesions can be examined histologically; and, by further passage in animals and eggs, the virus can be established and identified. The use of monkeys in such an investigation has not been mentioned because they are expensive and not essential, though, if available, one or possibly two might be inoculated intracerebrally. And it has been assumed that eggs, if available, will be used in parallel with the animals.

Psittacosis group.-Another example of the use of animal inoculation, in addition to eggs, in the diagnosis of virus infection is provided by diseases caused by viruses of the psittacosis group. Human infection with psittacosis virus is often associated with some degree of pneumonia, and either sputum or lung puncture material can be used for animal inoculation, though in psittacosis pneumonia sputum is often scanty. The mouse is the animal usually employed; and, if sputum is the material chosen, the presence of bacteria, particularly the pneumococcus, may introduce a complication. Though the bacteria can be got rid of by filtration, this also reduces the amount of virus, and a better procedure is to protect the mouse against the bacteria by means of sulphonamides, to which psittacosis virus is insensitive, or relatively so. This procedure has the additional advantage, if the mice have been inoculated by the nasal route, of preventing a lighting up of latent infection of the mice with the virus of Nigg (Nigg and Eaton, 1944), present in many mouse stocks. This virus belongs to the Castaneda-positive group and is fortunately susceptible to sulphonamides. And, in connexion with the use of mice for the isolation of psittacosis virus, it is important that both the intranasal and intraperitoneal routes of inoculation should be employed, because certain strains of psittacosis virus produce only an inapparent infection when introduced into the peritoneal cavity. This is true of pigeon strains, and here it might be pointed out that the host range of this virus is much more extensive than was at one time thought. In addition to birds of the parrot tribe, certain species of finch, fulmar petrels, pigeons, the domestic fowl, and ducks have been found to suffer from natural infection with psittacosis virus and to be responsible for human infections.

\section{Serological Investigation}

It is still far from being widely appreciated that those serological tests which are in daily use in the identification of bacteria and the diagnosis of bacterial disease are equally applicable to viruses. Virus workers themselves have been to some extent responsible for the tardy recognition of this fact. There is no need here to consider the reasons for this ; it is sufficient to note that it is now well established that the precipitin, agglutination, and complement fixation tests are all available for the investigation of viruses and the diseases they cause. And, because it is more difficult to obtain a suspension rich in virus than is the case with a bacterium, the complement fixation test is the serological reaction which has been found most suitable for virus work, since, as Merril has shown (1936), this test has a lower antigen threshold than the precipitin or agglutination reactions. A serological test could be used in the diagnosis of a virus infection either for the purpose of demonstrating the presence of virus in the infective material or for the detection of antibodies formed in response to the infection.

Demonstrating virus in infective material.-As an example of the former we have the use of the complement fixation test in the diagnosis of smallpox. Craigie and Wishart (1936) have shown that this is a reliable test for the presence of variola antigen in the vesicle fluid or in an extract made from the crusts of older skin lesions; the serum employed is one made against vaccinia virus in the rabbit. Tulloch (cited by Downie, 1946) has had wide experience of this test in the outbreaks of smallpox which occurred in Scotland in the war 
of 1939-45; he considers the test to have. a high diagnostic value. This opinion is shared by Downie (1946), who found that vesicle fluid or crusts from twenty-two cases suspected of being smallpox on clinical or epidemiological grounds gave a positive result; his material came from twelve different outbreaks. Similar material from other conditions, such as varicella, zoster, or septic skin rashes, gave a negative reaction. He concludes that this is the most valuable single laboratory test available for the diagnosis of smallpox, an opinion which seems fully justified by the evidence.

This is one of the few examples, however, of this particular use of serological reactions in the diagnosis of human virus infections. It has, at times, been applied, in conjunction with animal inoculation, for the differentiation of zoster from herpes simplex, using a known positive convalescent zoster serum and the fluid from the vesicular eruption (Bedson, unpublished observations).

Detection of antibodies.-But, generally speaking, the concentration of antigen in infective material from virus infections is too low even for its detection by the complement fixation reaction, and it is for this reason that the indirect use of such a test (that is, for the demonstration of specific antibody in the patient's serum) is of so much wider application as a diagnostic procedure. It would be impossible here to give a comprehensive survey of this use of the complement fixation test; a few illustrative samples will have to suffice.

Lymphocytic choriomeningitis.-In the course of infection with the virus of lymphocytic choriomeningitis, complement fixing antibodies are developed (Smadel and others, 1939) for the soluble antigen of this virus. Although these antibodies have probably nothing to do with immunity to this virus, they are specific and their presence diagnostic (Smadel and others, 1939; Lépine and Sautter, 1938). The soluble antigen is present in considerable amount in the tissues of the experimentally infected animals, and a suspension of the spleens of guineapigs succumbing to lymphocytic choriomeningitis provides a satisfactory antigen which remains stable when stored in the refrigerator for months or even a year or more. It is important to note that a freshly made spleen suspension may give false reactions, it should be allowed to age for two to three weeks before use. Although the American and French work already referred to leaves no doubt as to the specificity and diagnostic value of this test, limited experience of its use in this country has been disappointing (Bedson, unpublished findings). Dur- ing the war a number of sera from cases of benign aseptic meningitis have been examined without obtaining a single positive result, and, although in some of these cases this was probably due to their not being caused by the virus of Lillie and Armstrong, there were two from which this virus was isolated by mouse inoculation.

Influenza.-The complement fixation test can also be applied to the diagnosis of influenza (Smith, 1936; Hoyle and Fairbrother, 1937; Fairbrother and Hoyle, 1937; Francis and Magill, 1937; Tulloch, 1939), but since antibodies to influenza virus are to be found in detectable though low titre in the blood of most adults and older children, diagnosis depends on demonstrating a significant increase in these antibodies, and that makes the findings mainly of retrospective interest. This being so the neutralization test, which takes so much longer to do, might equally well be employed, and in the past it is the neutralization test which most workers have used. It may be, of course, that the Hirst phenomenon of agglutination of the red cells of the domestic fowl by influenza virus (1941), which is specifically inhibited by influenzal antibody and can be used as a method of antibody titration, will eventually largely replace both complement fixation and neutralization tests.

Virus agglutination of $r, d$ cells.-The subject of virus agglutination of red cells, which, since Hirst's original work, has been the object of much study, principally by Burnet and his colleagues in Australia, leads to mention of a recent observation from Burnet's laboratory. This is not the place for any detailed consideration of all the interesting work done in this field; suffice it to say that the phenomenon of red-cell agglutination is not confined to the influenza virus and chick cells; other viruses will do this, and the red corpuscles of certain species of mammal, including man, are agglutinated as well as chicken red cells. The absorbed virus responsible for the agglutination is liberated after a few hours; this fact, incidentally, is utilized in the concentration of the influenza viruses in the preparation of influenza vaccine.

The recent observation of Burnet and Anderson (1946) to which it is desired to draw attention is that human red cells which have been agglutinated by the virus of Newcastle disease of fowls and from which the virus has been eluted have become susceptible to agglutination by the majority of sera from recent cases of glandular fever. This work is still in its initial stages. The evidence produced by Burnet and his colleague suggests that the change in 
the cells is due to the absorption of antigenic material, other than virus, produced by Newcastle disease virus when growing in chick embryo cells. Burnet (1946) has also shown that human red cells treated with egg-grown mumps virus provide a sensitive test for mumps antibody in human sera.' Although much remains to be done, this work opens up such exceedingly interesting possibilities that it seemed well worth mentioning.

Psittacosis-lymphogranuloma venereum group.-It is perhaps in the diagnosis of iffections with the viruses of the psittacosis-lymphogranuloma venereum group that the complement fixation test has been most widely applied. This test has been used in the diagnosis of psittacosis in man (Bedson, 1935 and 1937) for eleven years or more, and the work of Meyer and his colleagues and others in America has confirmed its value. By means of this test support was given to the findings of Haagen and Mauer (1939) that cases of an atypical pneumonia occurring in the Faroe Islands were due to psittacosis or some very closely related virus, and it was used to show that a similar clinical condition in Iceland had a like aetiology (Bedson, 1940). Infection in these cases originated in fulmar petrels. Some involvement of the lung is of frequent occurrence in human infections with psittacosis virus, and it has long been recognized that the resulting pneumonia was unlike bacterial pneumonia in its clinical signs and histological picture. It was not, therefore, very surprising when Eaton and others (1941) showed that some cases of the condition known as primary atypical pneumonia, which in the recent war assumed almost epidemic proportions in this country and elsewhere, were due to psittacosis virus. This observation was based on isolation of the virus from sputum or lung material and the demonstration of a positive complement fixation test with the patients' sera. Subsequent work has shown that an appreciable proportion of cases presenting this syndrome, which Reimann (1946) quite rightly prefers to name "virus pneumonia," are due to viruses belonging to the psittacosis group. Smadel (1943), for instance, found that some 15 per cent of forty-five cases of so-called primary atypical pneumonia were probably due to a psittacosis virus, and, in a serological survey made of this condition in England during the war, nine cases out of 120 had a very high or rising titre of antibody for psittacosis virus (Bedson; unpublished findings).

The more extensive use of the psittacosis complement fixation test resulting from these investigations has shown that the mere presence of such an antibody in the serum of an individual does not necessarily mean active infection with a virus of this group. As in the use of any serological test for antibody as a diagnostic procedure, the demonstration of a rising titre of antibody is necessary to postulate active infection. Smadel (1943) rightly insists that only a fourfold rise in psittacosis antibody should be accepted as evidence of active infection, and with this the writer would fully concur. The recent work in America showing that the viruses belonging to the Castaneda-positive group are closely similar in antigenic structure has introduced a further complication. Rake and others (1941) found that sera from patients infected with the viruses of lymphogranuloma venereum and the psittacosis group all cross-reacted when tested by the complement fixation test with these viruses. They further showed that cases of atypical pneumonia due to a psittacosis virus might give a positive Frei test. And the demonstration by Rake and others a year later (1942) that the sera from cases of trachoma and inclusion conjunctivitis may fix complement with the antigens of lymphogranuloma virus suggests that these two viruses also share antigens with the psittacosis-lymphogranuloma group. There is further evidence obtained from cross-immunity experiments in animals confirming the close relationship between the viruses of the psittacosis group-parrot psittacosis, pigeon psittacosis or ornithosis, and the virus isolated by Eaton and others from atypical pneumonia-and the virus of lymphogranuloma venereum. How close this relationship will prove to be remains to be seen, but the immediate practical bearing of this work is that the serological tests which have been accepted in the past as specific for psittacosis and lymphogranuloma venereum can no longer be so regarded. And the Frei test, as one might expect, would appear to be no more specific than the serological tests. Though this does not mean that these tests are without value, it does emphasize the importance, which of course always existed, of invariably interpreting them in conjunction with the clinical findings.

\section{General Remarks}

This account of the part which the laboratory can play in the diagnosis of virus infections is far from complete. Only the more important examples of this have been mentioned, and they have been given shorn of much detail and supporting evidence. It is hoped, however, that this paper will have shown that the laboratory can be of help, not just occasionally by making some special investigation, but in an everyday routine way. 


\section{LABORATORY DIAGNOSIS OF VIRUS INFECTIONS}

\section{REFERENCES}

Armstrong, C., and Lillie, R. D. (1934). Publ. Hlth. Rep. Wash., 49, 1019.

Bedson, S. P. (1935). Lancet, 2, 1277

Bedson; S. P. (1937). Lancet, 2, 1477.

Bedson, S. P. (1940). Lancet, 2, 577.

Beveridge, W. I. B., Burnet, F. M., and Williams, S. E. (1944). Austral. J. exp. Biol., 22, 1.

Borrel, A. (1904). C. r. Soc. Biol., Paris, 57, 642.

Burnet, F. M. (1946). Brit. J. exp. Path., $27,244$.

Burnet, F. M. (1946). Brit. J. exp. Path., 27, 244. 27, 236.

Burnet, F. M., Beveridge, W. I. B., Bull, D. R., and Clark, E. (1942). Med. J. Austral., 2, 371

Craigie, J., and Wishart, F. O. (1936). Canad. Publ. Hlth. J., 27,371 .

Downie, A. W. (1946). Mon. Bull. M.O.H. and E.P.H.L.S., 5, 114.

Downie, A. W., and Dumbell, K. R. (1947). Lancet, 1, 550. Eaton, M. D., Beck, M. D., and Pearson, H. E. (1941). 'J. exp. Med.,

Fairbrother, R. W., and Hoyle, L. (1937). J. Path. Bact., 4, 213.

Francis, T., jun., and Magill, T. P. (1937). J. exp. Med., 65, 251.

Gordon, M. H. (1937). Edinb. med. J., 44, 65.

Gutstein, M. (1937). J. Path. Bact., 46, 313.

Haagen, E., and Mauer, G. (1939). Dtsch. med. Wschr., 65, 13.

Halberstaedter, L., and Prowazek, S. von (1907). Arb. Gesundh. Amt. 26, 44.

Hirst, G. K. (1941). Science, 84, 22

Hirst, G. K. (1942). J. Immunol., 45, 293.
Hirst, G. K. (1945). Proc. Soc. exp. Biol., N.Y., 88, 155.

Hoyle, L., and Fairbrother, R. W. (1937). Brit. J. exp. Path., 16, 425.

Lépine, P., and Sautter, V. (1938). Ann. Inst. Past., 61, 519.

Lindner, K. (1910). Wein. klin. Wschr., 23, 283.

MacCallum, F. O., Findlay, G. M., and Scott, T. McN. (1939). Brit. J. exp. Path., 20, 260.

Merril, M. H. (1936). J. Immunol., 30, 169.

Nigg, Clara, and Eaton, M. D. (1944). J. exp. Med., 79, 497.

North, E. A., Broben, J. A., and Mengoni, A. H. (1944). Med. J. Austral., 1, 437.

Paschen, E. (1906). Minch. med. Wschr., 53, 2391.

Rake, G., Eaton, M. D., and Shaffer, M. F. (1941). Proc. Soc. exp. Biol., N.Y., 48, 528.

Rake, G., Shaffer, M. F., and Thygeson, P. (1942). Proc. Soc. exp. Biol., N.Y., 49,545 .

Reimann, H. A. (1946). Arch. intern. Med., 78, 447.

Rooyen, C. E. van, and Illingworth, R. S. (1944). Brit. med. J., 2, 526.

Sabin, A. B., and Aring, C. D. (1942). J. Amer. med. Ass., 120, 1376

Shope, R. E., Maurer, F. D., Jenkins, D. L., Griffiths, H. J., and Baker, J. A. (1946). Amer. J. vet. Res., 7, 152.

Smadel, J. E. (1943). J. clin. Invest., 22, 57.

Smadel, J. E., Baird, R. D., and Wall, M. J. (1939). Proc. Soc. exp. Med., N.Y., 40, 71.

Smith, W. (1936). Lancet, 2, 1256.

Sorsby, A., Hoffa, Elizabeth E., and Young, Elizabeth N. (1944). Brit. J. Ophthal., 28, 451.

Thygeson, P., and Proctor, F. I. (1935). Arch. Ophthal., N.Y., 13 1018.

Tulloch, W. J. (1939). Edinb. med. J., 46, 117. 